\title{
"Journal of Basic and Applied Pharmaceutical Sciences": five decades of Brazilian scientific publication and contribution to the Pharmacy Area
}

\author{
Armando da Silva Cunha Junior ${ }^{1 *}$ (1) \\ 'Faculdade de Farmácia, Universidade Federal de Minas Gerais (UFMG), Belo Horizonte, MG, Brasil \\ *Corresponding author: armando@ufmg.br
}

Two thousand and twenty, a strange year! In addition to social, economic, political and environmental problems, a serious global health crisis caused by COVID-19 has been plaguing our country even more. This year also regrets an intense process of denying science, disseminating false information and public speeches that deny social advances have been consolidated over the past decades. The Brazilian scientific community has tried, in the midst of so many adversities, to combat the harmful consequences that this scenario of disinformation causes in our society. In this context of difficulties and challenges, based on its fifty years of experience and aware of the importance of quality scientific dissemination for the country's development, the "Journal of Basic and Applied Pharmaceutical Sciences" launches its new editorial policy and creates the tools to provide, with quality, scientific production of Pharmaceutical Sciences and related areas.

Nineteen sixty-seven, a very troubled year! The National Security Law came into force, a new Constitution was enacted, the Republic of the United States of Brazil was renamed Federative Republic of Brazil and the student movement arose against the military dictatorship instituted by the 1964 coup d'état. In the international context, the Cold War intensified, American youth demonstrated against the war in Vietnam and a new influenza virus started to spread, which would cause, in the following year, a worldwide pandemic causing thousands of deaths and the cancellation of different events all over the planet. It is also in this context of difficulties and challenges that, out of a bold initiative by a group of professors from the Faculty of Pharmacy and Dentistry of Araraquara, the journal "Revista da Faculdade de Farmácia e Odontologia" was created, in order to disseminate scientific advances in the two areas of knowledge involved.

In the year the journal "Revista da Faculdade de Farmácia e Odontologia" was created less than thirty Higher Education Institutions offered undergraduate courses in Pharmacy in the country. A very different situation from the current one, there are hundreds of undergraduate courses in operation and that can be pointed out as a direct consequence of the entry into force, in 1997, of the Law of Guidelines and Bases (LGB). In the 1960s, the Brazilian stricto sensu Postgraduate program was already taking its first steps. In the Area of Pharmacy, the first Postgraduate Program would only be created in the following decade, with a Master's degree at the Federal University of Rio Grande do Sul (in 1970), followed by the creation of five more Postgraduate Programs: three at the University of São Paulo, one at the Federal University of Paraíba and, one at the Federal University of Pernambuco. In the same decade, the Journal changed its name to "Revista da Faculdade de Ciências Farmacêuticas" and later to "Revista de Ciências Farmacêuticas", restricting its scope to the dissemination of scientific advances in the Pharmaceutical Sciences field. 
In the 1980s, ten volumes of "Revista de Ciências Farmacêuticas" were published. These are difficult years for Science in Brazil and especially for the Pharmacy Area, with only two more Postgraduate Programs coming into operation in a whole decade: one at the University of São Paulo (Ribeirão Preto campus) and the other at the Federal University of Rio de Janeiro. Most of the existing programs only offered Master's courses and only three had Doctorate ones. In 1990 the area finally begins to expand due to the increase in the number of qualified professors, trained both in the country and abroad, in addition to the creation of the Pharmacy Area Coordination in the "Coordenação de Aperfeiçoamento de Pessoal de Nível Superior - CAPES" (The Coordination for the Improvement of Higher Education Personnel).

In 1997, two Postgraduate Programs started being offered at the School of Pharmaceutical Sciences of Universidade Estadual Paulista "Júlio de Mesquita Filho", scratch that one in Clinical Analysis, with both Master's and Doctorate courses, and the other in Pharmaceutical Sciences, only with a Master's degree. In 2005, CAPES recommended the creation of a Doctorate course in the Pharmaceutical Sciences Program and, in 2008, the Clinical Analyzes Program was reformulated in order to "encompass new areas to better meet the evolution of research", becoming "Biosciences and Biotechnology Applied to Pharmacy" Program. In the last CAPES assessment, for the 2013-16 quadrennium, these two Postgraduate Programs were assessed as programs of excellence, which meet international quality standards.

From the 2000s onwards, a period of marked evolution for the Pharmacy Area in the country began, with emphasis on the creation, in 2003, of the Associação Brasileira de Ciências Farmacêuticas (ABCF), which hosts a Forum of Coordinators of Postgraduate Programs in the Area, and the creation, in 2004, of the Pharmacy Advisory Committee in the National Council for Scientific and Technological Development (CNPq). In 2005, the editors of the Journal "Revista de Ciências Farmacêuticas" and the Board of the School of Pharmaceutical Sciences, attentive to the advances in Pharmaceutical Sciences and related areas, as well as the impacts caused by the digital transformation in the media, decided to reformulate the Journal, which changes its name to "Revista de Ciências Farmacêuticas Básicas e Aplicada (RCFBA) - Journal of Basic and Applied Pharmaceutical Sciences" (volume 26, no. 1).

The online publications begin with the same volume, following the worldwide trend of this sector in making content freely available. As of 2013, the Journal started being published only in the digital version (volume 34). However, it should be noted that RCFBA remains true to its comprehensive scope of vehicle for the dissemination of articles from the different sub-areas of the Pharmaceutical Sciences, such as drugs and medicines, pharmaceutical assistance, pathophysiology of diseases, clinical analysis, and related topics.

In the period from 2013 to 2019, among the Journals edited by Higher Education Institutions in Brazil or belonging to Brazilian scientific societies, the Pharmacy Area is the predominant area from 11 journals ("Mother area": highest proportion of articles published in each Journal among the 49 different evaluation areas). Together, these journals published 3,211 articles, of which 1,297 were papers linked to the theses and dissertations of the Postgraduate Program in Pharmacy Area. The available indexing information for these journals indicates that, during the period considered, three were in Scopus' database and, together, accounted for $80 \%$ of the total articles published by the Postgraduate Program in Pharmacy Area. The RCFBA, one among the indexed journals, published $17.4 \%$ of that total. Of the 207 articles published by RCFBA in the period, 179 (86.5\%) were products of research linked to the work of Postgraduate Program in Pharmacy Area.

In the present moment, the Pharmacy Area has 70 Postgraduate Programs, comprising 111 courses, being 59 Academic and 8 Professional Master's Degrees and 43 Academic and 1 Professional Doctorates. Among the Postgraduate Programs in the area, seven have been assessed as programs of excellence. This important growth in the area in these five decades of history demonstrates the resilience, the qualification and motivation of the researchers of the country involved in the Pharmaceutical Sciences. The RCFBA, since its creation, with other names and formats, has contributed to the growth of Brazilian science. The Journal is a witness to the evolution of the Pharmacy Area and has already proven its importance as a vehicle for disseminating studies produced by Postgraduate Programs in the area. Therefore, 
the time has come for the RCFBA to also work towards its internationalization and seek its indexation in the most prestigious databases. With these objectives in mind and believing in a successful future, the Editors of the RCFBA publicize the new editorial policy and invite the scientific community to continue to honor the Journal as both readers and authors.

Armando da Silva Cunha Junior, PhD

Full Professor - Faculty of Pharmacy of the Federal University of Minas Gerais -UFMG, Belo Horizonte, Minas Gerais, Brazil. Editors-in-Chief 